\title{
SOCIAL RESEARCH REPORTS
}

ISSN: 2066-6861 (print), ISSN: 2067-5941 (electronic)

\section{ETHICAL ASPECTS OF COMMERCIAL SURROGACY}

\section{Racheli SILVERN, Stefan COJOCARU}

Social Research Reports, 2020, Vol. 12, Issue 2, pp. 9-16

The online version of this article can be found at:

www. researchreports.ro

\section{https://doi.org/10.33788/srr12.2.1}

Published by:

Expert Projects Publishing House

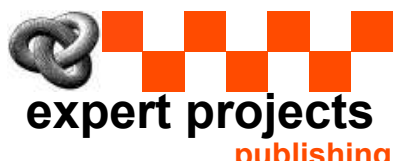

publishing

Covered by Index Copernicus International

www.indexcopernicus.com

Directory of Open Access Journals

www.doaj.org

On behalf of:

Center for Program and Social Development

Aditional services and information about Social Research Reports can be found at:

www.researchreports.ro 


\title{
ETHICAL ASPECTS OF COMMERCIAL SURROGACY
}

\author{
Racheli SILVERN ${ }^{1}$, Stefan COJOCARU ${ }^{2}$
}

\begin{abstract}
Surrogacy is an initiated process, whereby intended parents wish to have a child by having an embryo carried in another woman's womb and, after the birth, the baby is given to the intended parents. In Israel, giving birth and motherhood are perceived to great extent as a significant, essential and natural component of female identity and the existence of children is perceived as a vital and central element of couple-hood and family. The Israeli society encourages fertility and family expansion. This is illustrated by the support of surrogacy and fertility treatments pursuant to the Israeli Embryo Carrying Agreement Law (Agreement Authorization and Status of the Newborn Child) legislated in 1996. On the other hand, the government limits the supply of contraceptives that are included in the authorized list of medicines, pursuant to the State Health Insurance Law (Ministry of Health, 1994). Surrogacy constitutes a solution for people who wish to give birth to a child but they are unable to do so. The issue raises ethical dilemmas in the global village in which we are living. This dilemma has become more prominent in the present age, due to the corona virus crisis that entailed cancelling all flights and forcing each country to close its borders to foreign travelers. In this study, the aim is to explore and comprehend the process of surrogacy according to the economic sociological theory, called the agency theory; the relationships between the parties to the agreement; and the ethical issues stemming from this issue.
\end{abstract}

Keywords: surrogate, full surrogacy, partial surrogacy, intended parents, pregnancy, ethics.

\footnotetext{
${ }^{1}$ Department of Sociology and Social Work, Alexandru Ioan Cuza University from Iasi, ROMANIA. E-mail: rachel_44@walla.co.il

${ }^{2}$ Department of Sociology and Social Work, Alexandru Ioan Cuza University from Iasi, ROMANIA.E-mail: contact@stefancojocaru.ro
} 


\section{Introduction}

The present study aims to explore the ethical views and considerations with regard to surrogacy. In 1991, Arlette Schweitzer, a librarian from Aberdeen, South Dakota, became the first woman in history to carry her grandchildren in her womb (Los Angeles Times, 1991). Since her daughter was unable to carry the fetuses in her womb, Switzer would do it for her. Her daughter's fertilized eggs were therefore implanted in her womb, and nine months later she gave birth to twins, a boy and a girl. Bringing a child into the world has always been one of the most meaningful actions in people's life. Unfortunately, not everyone can do it in the natural way, due to various medical problems. The cutting-edge technology allows having a child through full or partial surrogacy. However, the rapid development of this technology, which encompasses many benefits, gives rise to moral and ethical questions. Full surrogacy is a situation, whereby the surrogate, namely the mother who carries the baby, does not take part in the genetic weight. That is, both the egg and the sperm come from the intended parents and the fetus is transferred to the womb of the carrying mother (Benshushan \& Schenker, 1997). Legitimizing surrogacy in Israel ) She carries it during the pregnancy and, after the birth, the baby is delivered to the intended parents. Partial surrogacy or in another name called Traditional Surrogacy ( Levron, 2015 ) is not alaud in Israel is a process, whereby the surrogate donates the egg. This mainly concerns same-sex couples or women who for some reason have no eggs or are unable to conceive. In these cases, the woman who undergoes the pregnancy process is also the donor of the egg.

This paper discusses the ethical issues presented in the empirical literature as to relations of exploitation of the surrogate and to an informed consent for the surrogacy process. Some researchers argue that surrogacy is an exploitation of the weak population. Moreover, those who advocate individuals' rights (e.g. Mandel \& Margalit, 2014; Shapiro, 2014), argue that women have a right for autonomy on their bodies and this right must be observed. In addition, this does not concern a dimension of exploitation but rather an improvement of the women's economic situation.

Another argument relates to the issue of informed consent. This issue raises the questions whether the surrogate mother has indeed entered the surrogacy process out of her own free will and has fully understood the process. Mandel and Margalit (2014) argue that women undergo a hormonal medication treatment that might affect their judgement. There are women for whom this is the first pregnancy and they have no experience, Thus, there is not really an informed consent for engaging in the surrogacy although the surrogate mother has agreed and is willing to do it.

In this paper I maintain that this process constitutes exploitation of the weak population. These women are forced to agree to the terms of the contract, due to the necessity to improve their economic situation. Hence, the consent is not entirely informed. I will try supporting my claims on the basis of the agency theory (Ross, 1973) that advocates contractual relationships between two parties, when each party to the contract strives to maximize its gains. 


\section{Literature review}

Surrogacy is a global issue (U.S. Government, 2016). The Permanent Office in The Hague estimates that this industry has grown by a thousand percent between 2006 and 2010 alone. Reviewers (Finkelstein et al., 2016) maintain that the industry currently generates some $\$ 6$ billion annually. In fact, acorrding to Finkelstein et al. (2016) the international surrogacy industry has increased dramatically and continuously over the past five years. Every year, thousands of children are born worldwide via surrogacy but only very limited general data exist on trends in surrogacy beyond the numbers of annual births. This is due to the fact that even in countries which have legalized surrogacy, governments do not monitor its scope. Moreover, it is difficult to compile reports due to a parent or a couple's choice of surrogacy abroad, or their unwillingness to report their choices because of concern over social acceptance and / or the procedure illegality. This situation creates problems in both sociological and legal aspects. In the sociological aspect there is difficulty in the admission of children and parents to society, there are no registrations of children, it is not possible to track whether they come to kindergartens to schools, protection of children's rights as they allegedly do not exist in the country where they live. In the legal aspect may create problems of registrations in government offices, subsequent marriage, driver's license, criminal etc.

In Israel, motherhood and birth are perceived to great extent as a defining trait, vital, a natural element of feminine identity, and children are perceived as a vital and central component of couple-hood and are focal to the sense of family. Israeli society encourages fertility and expansion of the family, so that fertility treatments and surrogacy are promoted by being included in the health package rather than preventing the use of contraception (Ministry of Health, 1994).

A qualitative study that was conducted in India (Arvidsson et al., 2017) investigated positions towards surrogacy. The findings indicated differences of opinion concerning various aspects of surrogacy, i.e., that of the surrogate, of the intended parents and the babies born out of surrogacy. From the aspect of the surrogate, the study argued that the surrogates entered the project from a point of weakness, these women are exploited and their rights are violated. Moreover, Shapiro (2014) stipulates that surrogate women, who usually belong to a low socioeconomic class, experience exploitation of their status for the purpose of surrogacy. As mentioned above, I will relate to these issues according to the agency theory that specifies the contractual relationships between the parties to the contract.

The economic sociological theory, called the agency theory, is a classic theory in corporate economics literature, originally presented by Ross (1973). Kathleen Eisenhardt (1989) describes in her article that one of the main perspectives of the theory is the contract which establishes the relationship between the two parties. The theory explains two-sided relationships (such as those that exist between employers and employees, whose goals are incompatible). The core assumptions 
of this theory are that humans are self-interested individuals, think about their own good and avoid taking risks. Hence, each side acts in order to maximize what is best for it in any situation. The theory can be applied on a personal or organizational level. In the contractual system, people can choose whether to tie themselves to one or more of the contracts that comprise the deal, in which status and under which conditions. The rights, duties and rules of conduct are binding upon the parties.

\section{Surrogacy in light of the Agency theory}

When analysing surrogacy by means of the agency theory, the contractual relationships between the parties can be indicated as the basis (Ross, 1973). On the one side of the contract is the surrogate (the agent) and on the other, the intended parent (the principal, owner of the capital). This contract between the parties apparently expresses the wishes which the parties have agreed upon. The contracts include terms that have been negotiated in detail between the parties. These terms are dictated by one party, usually the strong one, namely the intended parents who belong to the middle class and above, since the amount of money necessary for the surrogacy is high even in developing countries. The other side to the contract, the weaker side, can decide whether to join and at what price. There are dispositive terms, that is terms that are negotiated and can be bargained but they are accepted in the field of surrogacy. For example, dispositive terms can be conditions regarding the requirement to quit smoking, in terms of nutrition to eat vegetarian food. There are also constitutional terms, i.e., terms set down by law or decree as an 'authorizing norm' and cannot be amended. For example, terms of The Israeli Embryo Carrying Agreement Law which maintains that he Contract must be submitted to a committee on behalf of the Ministry of Health that will approve the contract, without the approval it is not possible to start a process of surrogacy in the Israel. Surrogacy is approved only for a man and woman couple or for a single woman and is not approved for a couple of men (Ministry of Health, 1996).

\section{Ethical issues related to surrogacy}

From an ethical point of view, when the intended parents choose the surrogate, this entails contractual relationships with the intended parents (the manager, according to the agency theory) paying a certain amount of money to receive the surrogate's service (the agent) (Ross, 1973). The intended parents feel ownership of the surrogate and want to create an optimal pregnancy for the baby that is to be born. Through a pre-pregnancy contract, they make the surrogate sign the terms of the contract that usually serves the intended parents. This contract sets terms for the pregnancy and post-natal procedures, stipulating rules of conduct under the contract agreed upon between the parties. Furthermore, there are restrictions on the surrogate, such as: prohibition to smoke, Cesarean section, healthy nutrition, gynaecologist care, stopping to work, etc. The surrogate must fulfill the terms of her contract to the letter so that she can receive her payment, in exchange for the intended parents receiving a healthy baby for the amount of money they agreed to pay (Triger, 2015). 
Women, who agree to act as surrogate, lease out their body. The human body is perceived as people's personal and private property and they have the right to use their body for the purpose of procreation. This decision is made out of the woman's free will rather than out of commercial motives. Using the woman's body for commercial motives is considered despicable and humiliating. Many people maintain that using women's body for their livelihood by means of prostitution and pornography is a legitimate, though contemptible and degrading means of providing for themselves. Surrogacy in fact is not attributed the same intensity of humiliation like prostitution and yet the number of women who are willing to serve as a surrogate mother is low and insufficient. Shapiro (2014) points out that we can relate to surrogacy as work without the involvement of emotions and preventing emotional attachment to the embryo once the surrogate knows her womb is for lease and it is used for work only. The main criticism against surrogacy is that it encompasses a dimension of exploitation of the weak party, i.e., the surrogate (Supra, 2009). In order to improve her economic situation, the surrogate consents to all the restrictions dictated to her.

In this Sense, the parties are not equal in power. There is the weak party, namely the surrogate mother who comes from a low socioeconomic status and is perceived as a victim of exploitation. The payment she receives for services rendered can indeed improve her economic situation. However, she can use the amount of money that she has received only for a certain period of time and enhance her economic situation during that period. Once the money has been spent, she goes back to the starting point. The restrictions dictated to the surrogate can be seen as violation of her autonomy (Ministry of Health, 1996; https://www health.gov.il/Legislation Library/Zchuyot_01.pdf) due to the decision which lifestyle to conduct. This is determined according to the intended parents' wish, manifested by the contract agreed upon between the parties.

\section{Issues related to informed consent}

From the informed consent aspect, it is difficult to acknowledge that the consent is informed. Pursuant to The Israeli Embryo Carrying Agreement Law (Ministry of Health, 1996) and The Patient Rights Act, Section 13 (State of Israel, 1996), in order to have an informed consent, several terms must apply. Among them are: the patient must receive an explanation about the process, the risks, changes and side-effects it involves, and about the fact that this is an innovative treatment, if applies. Tieu (2009) stipulates that the lack of past experience with pregnancy and birth and/or a hormonal medication treatment, can affect the surrogate's judgement. In order to obtain an informed consent, the surrogate should be lucid and free of the effect of chemical substances. During her first pregnancy and first birth, the surrogate does not have the ability to understand the implications of this situation, although she might have read about it. However, in practice, she has never experienced morning sickness, vomiting, overweight, pains, sick leave, and absenteeism from work.

Moreover, the surrogate asks herself whether the birth will be normal or by Caesarian section. After giving birth, what will be the restrictions she will have to deal with? Will she be able to go back to her place of work? Who will pay for 
the days she does not work? The surrogate's economic situation and her wish to improve it, prevent her from processing the dilemmas and do not allow her to object to the contractual terms presented to her.

Hence, she agrees to every term of the contract in order to receive the payment. Women who are willing to act as surrogate, do not take into consideration all the implications of the process and the improvement in their economic situation is only for a short period of time. One can point out that the surrogate is being exploited in order to satisfy the desires of the capital owner i.e. the parents who hired her surrogate services.

The intended parents relate to the surrogate and her body as if they were an object, her freedom and autonomy are violated and her physical and mental health might be harmed.

This criticism sheds light on the fact that usually there is a socioeconomic inequality between the intended parents and the surrogate. Thus, the surrogate depends economically on the intended parents and is willing to give up her right and autonomy because she needs the money (Supra, 2009). The decision to become a surrogate is not made freely; it is rather a choice made out of stress and difficult socioeconomic situation. This is not really an informed consent of the woman to become a surrogate. Illustrating that surrogacy is a sensitive and complex issue which should be better regulated so that the surrogate is not exploited and her rights are observed.

\section{Conclusion}

The surrogacy technology has passed a long way on the social, medical and legal level. However, there are still essential issues as far as using the surrogacy procedure is concerned. For example, how are the surrogate and intended mother perceived by the public? The more prevalent the surrogacy procedure becomes, the more intensified the aspect of the objectified and non-personal use of the surrogate's body. This use is humiliating by nature. In countries such as India, where the surrogacy industry is very common, there are today practices of "ordering" surrogacy children by mail, without any personal contact with the surrogate. Moreover, this entails the establishment of "conceiving children farms", housing many women who serve as human incubators for western couples, and living under very inhuman conditions.

Essentially, the surrogacy contracts are negotiated between sides with unbalanced power. The contracts are designed according to the needs of the intended couple that is the strong party to the contract, vis-à-vis the surrogate who is the weak party to the contract. These contracts usually include delivery of the child to the ordering couple, with no prolonged contact with the surrogate. Moreover, various restrictions are enforced on the surrogate's autonomy and freedom during the pregnancy and the birth. These restrictions aim to guarantee the optimal health of the embryo - the "possession" of the ordering couple that is "held" by the surrogate. 
This paper presents the customary arrangements from the legal aspect, in order to guarantee as much as possible that the surrogate's rights are not violated. I believe that these arrangements are insufficient and they should be reinforced by clear and detailed contracts. The questions raised in the contract should be clarified in order to avoid harming one of the parties and to observe the rights of the two parties to the contract. The wishes of the parties should be set down in the contract, based not on exploitation but rather on partnership, interrelations between the parties, mutual help and guarantee. It might be necessary to include the opinion of a social worker, who will express her position about the parties for the purpose of preventing relations of exploitation. Concerning the effect that the hormonal treatment might have on the surrogate's informed consent, women who wish to act as surrogates should receive all the explanations about the process, even before they start the hormonal treatment. Surrogates, who were pregnant and gave birth to babies before, should be preferred.

\section{References}

Arvidsson, P., Vauquiline, P., Johnsdotter, S., \& Essen, B. (2017). Surrogate mother praiseworthy or stigmatized: A qualitative study on perceptions of surrogacy in Assam, India, Global Health Action, 10. DOI: 10.1080/16549716.2017.1328890.

Benshushan, A., \& Schenker, K. G. (1997). Legitimizing surrogacy in Israel. Human Reproduction, 12(8), 1832-1834. DOI: 10.1093/humrep/12.8.1832

Eisenhardt, K. (1989). Agency Theory: An assessment and review. The Academy of Management Review, 14(1), 57-74. DOI: 10.2307/258191

Finkelstein, A., MacDougall, S., Kintominas, A., \& Olsen, A. (2016). Surrogacy law and policy in the U.S.: A national conversation informed by global lawmaking. Report of the Columbia Law School Sexuality \& Gender Law Clinic. https://web.law.columbia. edu/sites/default/files/microsites/gender-sexuality/files/columbia_sexuality_and_ gender_law_clinic_surrogacy_law_and_policy_report_-june_2016.pdf.

Levron, Y. (2015) What is the difference between partial surrogacy and full surrogacy. Retrieved on: https://ivf4you.com/

Los Angeles Times (1991). Surrogate Mother in S. Dakota Gives Birth to Grandchildren. https://www.latimes.com/archives/la-xpm-1991- 10-13-mn-1056story

Mandel, R., \& Margalit, M. (2014). I got cleaned up, had a baby for money. Retrieved from: ynet,.02.0.0702,http://www.ynet.co.il/articles/0,7340, L-4480459,00.html. [Hebrew]

Ministry of Health (1994). State Health Insurance Law. Jerusalem: Ministry of Health. https://www.nevo.co.il/law_html/law01/036_001.htm [Hebrew]

Ministry of Health (1996). The Israeli Embryo Carrying Agreement Law (Agreement Authorization \& Status of the Newborn Child). Jerusalem: Ministry of Health. Retrieved from: https://www.nevo.co.il/law_html/law01/113_001.htm [Hebrew]

Ross, S. A. (1973). The Economic Theory of Agency: The Principal's Problem, American Economic Review, 63(2), 134-139.

Shapiro, J. (2014). For a feminist considering surrogacy, is compensation really the key question? Washington Law Review, 89, 1345-1374. 
State of Israel (1996). The Patient Rights Act, Section 13. Jerusalem: State of Israel. [Hebrew] https://www.nevo.co.il/law_html/law01/133_001.htm

Supra, A. (2009). Not an Angel, Not A Whore: Surrogates as Dirty Workers in India. 16 Indian Journal of Gender Studies. DOI: 10.1177/097152150901600201

Tieu, M.M. 2009). Altruistic Surrogacy: The Necessary Objectification of Surrogate Mothers, J. Med. Ethics, 171, 172. DOI: 10.1136/jme.2008.024679

Triger, Z. (2015). Theory and Criticism Experiences of Israeli Surrogate Parents in India https://theory-and-criticism.vanleer.org.il/wp.../10/Teoria-44_Triger.pdf

U.S. Government (2016). Surrogacy Law and Policy in the U.S.: A National Conversation Informed by Global Lawmaking. Report of the Columbia Law School: Sexuality \& Gender Law Clinic. 